\title{
Every little helps
}

Novel techniques that could help to make human embryonic stem-cell research morally acceptable will not immediately defuse the ethical debate over the work.

\rceil his week, Nature is publishing online two papers describing new techniques for deriving embryonic stem cells. The limits on federal funding for human embryonic stem-cell research in the United States have inspired political lobbying and led to the creation of alternative funding sources and international networks to facilitate offshore collaborations. These papers mark a new approach: they are aimed at making human embryonic stem-cell research morally acceptable (see page 1076 ).

One group, from the Massachusetts-based biotechnology company Advanced Cell Technology, has used a single-cell biopsy procedure, similar to an in vitro fertilization (IVF) technique called preimplantation genetic diagnosis (PGD), to derive mouse stem cells without affecting the subsequent development of the donor embryo (Y. Chung et al. Nature doi: $10.1038 /$ nature $04277 ; 2005)$. The authors propose that human embryonic stem-cell lines could be created in the same way, using embryos that are already undergoing the IVF technique as donors, so there is minimal additional risk to the embryo.

One limitation of this method is that stem cells derived in this way would represent a limited gene pool restricted to the clientele of IVF dinics, who tend to be affluent and white. But a second method, reported this week by researchers at the Whitehead Institute, also in Massachusetts, would produce cells matched to any donor.

The altered nuclear transfer (ANT) method, which has been tested in mice, switches off a gene in the donor nucleus before it is transferred to the egg (A. Meissner \& R. Jaenisch Nature doi:10.1038/ nature $04257 ; 2005)$. The gene is necessary for the embryo to implant in the womb, so the embryo cannot develop beyond the implantation stage. William Hurlbut, a bioethicist at Stanford University in California and a member of the President's Council on Bioethics, argues that these embryos have neither the cellular organization nor the developmental potential of a normal embryo, and so need not be accorded the same moral status.
It remains to be seen if either method can do anything to resolve the political impasse over human embryonic stem-cell research. The PGD method was attacked in Congress earlier this year. Critics said that delaying the IVF procedure to allow one of the cells in an eightcell embryo, or blastomere, to divide into cells that can be used for both IVF and embryonic stem-cell culture exposes the embryo to more risk than normal. Geneticists and fertilization specialists must now decide whether the idea is worth testing in humans.

The ANT method, on the other hand, is predicated on the question of when life begins - a question that scientists can't answer and that non-scientists cannot agree on. Several Harvard scientists have argued that ANT would only make an already difficult procedure even more cumbersome, and delay progress on therapies (N. Engl. J. Med. 351,
"Now that the science has been reported, the advantages of both methods can be rigorously assessed." $2791-2792 ; 2004)$. Another question is whether there is a moral difference between making an embryo that is incapable of forming the tissue required for implantation, and stripping the tissue from the embryo after it has formed.

The ethical appeal of the approach has yet to be tested. If proponents such as Hurlbut are sufficiently numerous and influential, it could help to tip the balance towards a more benign regulatory and funding environment for human embryonic stem-cell research.

The scientific and ethical issues raised by these discoveries are complex, and by publishing these papers Nature is not endorsing either of them as a solution. Rather, we support the full funding of human embryonic stem-cell research using all available technologies, subject to tight ethical oversight. Now that the science has been reported, the advantages and disadvantages of both methods, as well as their feasibility in humans, can be rigorously assessed.

\section{An unhealthy practice}

\section{Prescription guidelines should not be written by people with financial conflicts of interest.}

\footnotetext{
$\Lambda$
} survey reported on page 1070 of this issue suggests that pharmaceutical companies often have financial links with the people who write guidelines on how physicians prescribe drugs. More than a third of the authors of such guidelines declared a financial connection to the companies that produced the drugs.

No one is suggesting that the authors in question are deliberately adjusting guidelines to match these interests: most of them surely have their patients' interests at heart. But that doesn't mean that the potential conflicts don't matter. In other areas of medicine - induding dinical trials and educational programmes - pharmaceutical money has been shown to exert a subtle influence on the choices made by physicians and researchers (see A. Wazana J. Am. Med. Assoc. $283,373-380 ; 2000$ ). So it is not unreasonable to assume that a similar effect is at work in the preparation of prescription guidelines.

Several simple steps could be taken to improve matters. The doctors' organizations that write most of the guidelines should require that authors fully disclose potential conflicts of interest and add their disclosure statements to the guidelines. This doesn't always happen now - despite widespread agreement that it's the right thing to do.

But disclosure is only a first step towards objectivity. The survey also revealed that about $10 \%$ of all guideline panels include an author who holds stock in a relevant company. These holdings should be 